Archived version from NCDOCKS Institutional Repository http://libres.uncg.edu/ir/asu/

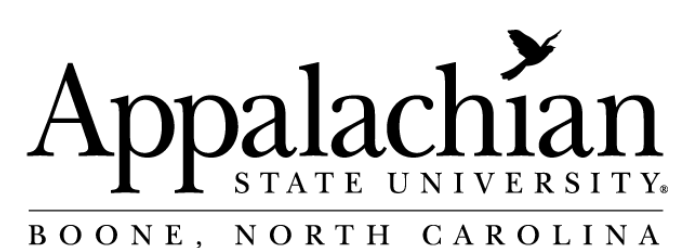

\title{
The genesis of a virtual world - revisited
}

\author{
By: Robert L. Sanders
}

\begin{abstract}
Constructing a virtual world requires certain technical skills and the ability to make difficult decisions regarding how the world will look and feel. However, the most difficult aspect of building a virtual world has less to do with the building of the virtual spaces and more to do the conceptualisation of how teaching and learning will occur in this new type of environment. This paper examines some of the issues involved in the process of planning a virtual learning world by focusing on key design questions that need to be asked prior to building virtual instructional spaces.
\end{abstract}

Sanders, Robert (2007). "The genesis of a virtual world - revisited." International Journal of Web Based Communities, [3(3), pp. 271-282.] Published by Interscience. (ISSN: 1477-8394) \{DOI: 10.1504/IJWBC.2007.014238\} 
Sanders, R.L. (2007). The genesis of a virtual world - revisited. International Journal of Web Based Communities, 3(3), pp. 271-282. Published by Interscience. (ISSN: 1477-8394) DOI: 10.1504/IJWBC.2007.014238

\title{
The genesis of a virtual world - revisited
}

\author{
Robert L. Sanders
}

\begin{abstract}
Constructing a virtual world requires certain technical skills and the ability to make difficult decisions regarding how the world will look and feel. However, the most difficult aspect of building a virtual world has less to do with the building of the virtual spaces and more to do the conceptualisation of how teaching and learning will occur in this new type of environment. This paper examines some of the issues involved in the process of planning a virtual learning world by focusing on key design questions that need to be asked prior to building virtual instructional spaces.
\end{abstract}

\section{INTRODUCTION}

Due to the recent increase in interest regarding the application of 3D virtual world technology to instructional settings, my department has committed to and invested in the necessary hardware, software, and technical support to expand the capacity for the development of virtual worlds in terms of size (virtual acreage), number (of 'worlds' and 'population'), and faculty involvement. As a result, I have recently been 'deeded' my own virtual plot to design and bui ld spaces to facilitate the courses I teach in my graduate programme. I understand from talking and observing my instructional technology colleagues that there is some skill involved in the actual building of the virtual spaces in which my students will eventually interact and learn. However, it is not in the construction process that I am most anxious. Rather, I am anxious about facing the more perplexing, philosophical, and theoretical questions I expect to have to answer; questions like, "What should teaching and learning look like in this world? How is teaching and learning in this new environment similar to and different from other online environments l've used in the past?" and, "How can our college's social constructivist conceptual framework and instructional design theory inform and guide my design of this new virtual teaching and I earning environment?" 
I have long subscribed to a more constructivist, holistic, exploratory approach to teaching and learning than to other more directed, didactic approaches. I have, however, found it more challenging to implement this more constructivist approach in an environment in which teaching and learning is mediated by technology. I have held blame the design of the learning management systems and other online tools I have been pr ovided for some of these challenges, arguing that these tools were designed with a behaviourist approach in mind, tending to support a more linear, sequential style of teaching and learning, in which a unit or course would consist of discrete lessons for the students to complete and master before moving on to the next. As a result, I have resisted using these popular learning management systems the way they were intended and have opted out of utilising some of the more traditional features they offer. I do take full advantage of their communication and collaboration tools, and have experimented with various ways to organise and s hare content, resources, and pr oject assignments that are more in line with my social constructivist framework. In spite of these attempts, I still feel that students are not truly engaged in my online courses they way I would like them to be and bel ieve that there may be 'better' tools available to create the type of constructivist learning environment that I envision.

It is my hope that as I now abandon these more traditional learning management systems and their inherent behaviourist designs, and move towards the use of new tools to design and create an immersive 3D virtual world, I will no longer be l imited by technologies designed for an approach to instruction that is diametrically opposed to what I believe about teaching and learning. Until then, all I can do is think, reflect, read, plan, design, and build. Along the way, I expect to encounter many challenges and confront many questions having to do with what teaching and learning looks like in this virtual world I am about to create. What follows are some of those questions I have already encountered and some thoughts on how I plan to address these questions as I continue with the design process.

\section{BODY OF PAPER}

\subsection{What might teaching and learning look like in this virtual world?}

To begin the design process I revisited our college of education's conceptual framework, which serves as a guide to guide the teaching and learning that occurs within the college. This framework is based on five assumptions supported by a rich theoretical and research base in the area of social constructivism (Reich College of Education, 2005):

1 Learning occurs through participation in a Community of Practice.

2 Knowledge is socially constructed and learning is social in nature in a Community of Practice.

3 Learners proceed through stages of development from Novice to Expert under the guidance of more experienced and knowledgeable mentors in the Community of Practice.

4 An identifiable knowledge base that is both general in nature and also specific to specialties emerges from the Community of Practice.

5 All professional educators develop a set of Dispositions reflecting attitudes, beliefs, and values common to the Community of Practice.

I have attempted to apply these core beliefs into the design of my online courses but have struggled with the limitations the tools put on the social construction of knowledge and the development of communities of practice, in particular. While e-mail, discussion boards, and chat 
rooms may offer ways for students to communicate and interact, they are typically used to simply recreate the types of interactions that take place in a face-to-face environment. As such, the knowledge that has been shared and the communities that have formed have been similar to what has occurred in my face-to-face courses. On one hand, it is reassuring that online courses can be 'as good' as a traditional face-to-face course. On the other hand, I believe the power in using a 3D virtual world is that teaching and I earning can be approached in a completely new and innovative way, which empowers students to fully realise the vision of our college's conceptual framework and inducts them into a true, socially constructed community of practice. This approach implies and even requires a level of presence, collaboration, and interconnectedness that I believe is difficult, if not impossible, to achieve in a more traditional distance learning environment. It requires tools that are designed around the belief that content should be driven by the usefulness of what is learned, needs determined by the students rather than assumed by the instructor or the content delivery system employed, usefulness of the courses should be linked to external value added rather than assumed, and opportunities for learners to interact frequently to build a community of practice (Watkins and Kaufman, 2003).

Having quality tools, however, does not always ensure that good instruction will occur. I have examined various examples of virtual worlds that were designed to resemble virtual classrooms in which a student's avatar enters a classroom, sits at a desk, and 'listens' to a lecture on the topic of the day. These literal recreations of traditional learning environment are uninspired examples of how learning technologies can be under utilised. In contrast, Riedl et al. (2005) have identified an approach in which students choose their own paths through a s eries of 'hypermazes' that contain information, resources, and discussions linked directly to students questions and experiences generated while exploring the maze. According to the authors: "These areas allow students to move to them and between them in a non-linear fashion according to their needs and i nterests with timeline for projects, sharing (discussion, brainstorming entries, etc.), establishing a flow for the class" (Riedl et al., 2005).

Those who design courses in which students are passive recipients of information approach teaching and learning from a much different theoretical perspective than those who create a learner-driven environment in which student are expected to engage in learning according to their needs and interests. I want my virtual world to be student-directed and exploratory in nature and for my students to engage in critical thinking, cross-disciplinary dialogue and activities. I want to provide a resource rich environment in which students have access to content available in a variety of media formats (video, still images, audio files, etc.) and make available to them tools to manage and manipulate this content to create, construct, and make meaning from the information. I want to be able to provide all this in a safe and motivating context in which learning is both risk-free and enjoyable, and in which learning takes place through interaction, meaning making, and collaboration with other students in the course. In other words, I want to design a virtual version of a social constructivist classroom that embodies the five assumptions of our conceptual framework.

\subsection{How might the teaching and learning differ between this world and other learning environments I have used in the past?}

Many learning management systems are designed with features and tools that reflect a didactic approach to instruction. These tools have allowed me to design sequential lessons and units, post a lecture (as a text, audio, or video file, or as a PPT presentation), and create quizzes and tests to ensure that my students have viewed that lecture, read the required course readings, and completed the assignments. Since this is not the way I approach teaching and learning, I 
have found these tools to be i nadequate for designing a c ourse using a $\mathrm{m}$ ore social constructivist approach to which I subscribe.

Riedl et al. (2005) support these concerns in stating that most online learning looks like traditional face-to-face learning and that there is nothing innovative in the use of the technologies available to us today to create engaging online learning experiences for our students. Subsequently, students end up doing the same lessons in an online course that they would in a face-to-face course. While this may be acceptable for some, I believe it is an unfortunate situation considering the powerful tools that are available to us as course designers and instructors, especially those tools embedded in the virtual world environment. These tools allow for a more immersive, metaphor driven environment that supports and encourages more personal interactions, collaboration, exploration, and discovery. The three-dimensionality of the virtual world also incorporates time, distance, and presence as important elements into its design and subsequently uses these elements to provide for more authentic learning opportunities than a flat, linear, online system ever could.

While a 3D virtual world offers many of the same online tools that other learning management systems provide (i.e., chat rooms, discussion board, web pages), the immersive nature and the inherent aspects of time and space have the potential of making the virtual learning environment more engaging and student-centred. Students have a sense of presence as defined by time and distance as a result of their using an avatar to move around within the world. This presence provides the opportunity to interact with others in the world, not only in formal ways designed within the context of a class activity, but perhaps more importantly, in informal or serendipitous ways as students casually meet others as they 'walk' from one space to another. This freedom of movement and the opportunity for both formal and informal interactions with others should not be underestimated. This feature of a virtual learning environment can be utilised in a variety of ways to support and $p$ romote several of the assumptions and beliefs of the conceptual framework discussed above, including but not limited to the idea that knowledge is socially constructed and that learning emerges out of a s tudent's involvement in a c ommunity of practice.

The social constructivist approach to teaching and learning is based upon the assumption that students need to work and learn within a community of practice. Fortunately, there is a growing body of research that focuses on the formation of virtual learning communities. While instructor and student work within these communities, each has different roles and responsibilities to ensure the viability of the community. Collins and Berge (2001) suggest that the instructor's role is to:

"Promote human relationships, affirming and recognizing students' input; providing opportunities for students to develop a sense of group cohesiveness, maintaining the group as a unit, and in other ways helping members to work together in a mutual cause."

The students, on the other hand, are responsible for 'using the guidance [of the instructor] in a meaningful way' and f or seeking solutions to real-world problems, asking questions, and critically evaluating their own learning through reflection and dialogue (Palloff and Pratt, 1999). In this type of virtual collaborative environment, students work together and ideally, with others outside of the course, to 'generate deeper levels of understanding and critical evaluation of the material under study' through sharing, discussing, providing feedback, and building connections between communities (Palloff and Pratt, 1999). Ultimately, a virtual world can serve as a foundation for a new and innovative approach to teaching and learning in which students become members of a cross-collaborative learning community (Riedl et al., 2005). 


\subsection{Does a pedagogy currently exist that can guide my design of the virtual world?}

Several design theories and pedagogies exist that may provide some guidance in the design of a virtual world. These include research in the area of metaphorical graphical user interface design, microworld learning environments, and Cyrs' IMPPACTs model.

Metaphorical teaching and learning environments found in 3D virtual worlds afford instructors many new possibilities for engaging students in different kinds of interactions than those found in other web based course development structures. The design of such experiences requires a close look at how interface metaphors are used to support exploration, knowledge acquisition, collaboration, and reflection (Bishop and Cates, 1996; Cates, 1994; Henry and Crawford, 2001; Sanders and Tashner, 2004). Metaphors can and should be complementarily aligned with one another to assist learners in developing a "conceptual framework of understanding through which the learner can further enhance prior knowledge and conceptualise a hi gher level of understanding towards the knowledge being obtained" (Henry and Crawford, 2001). A study conducted by Sanders and Tashner (2004) suggests that immersive metaphorical graphical user interfaces (Immersive MGUI) may offer students a more engaging and stimulating learning experience than what they would have in a non-metaphorical GUI environment and that the role of metaphors may be to offer a level of familiarity and comfort to students while providing more concrete ways for students to better connect with abstract ideas and concepts. Findings in this study also suggest that a virtual world must be well designed and provide students with a complex array of complementary metaphorical tools, activities, and content they can utilise and explore.

Papert's (1980) research in the design and use of microworld learning environments to engage learners in higher-order thinking is also relevant to the design of a virtual world. In a microworld "Knowledge, skills, and at titudes are integrated through problem-solving activities, and instruction is situated in rich meaningful settings" and that "microworlds are exploration environments that exploit the interest and curiosity of the learner, so they must contain phenomena that learners are interested in. They incorporate instructional strategies such as modelling, coaching, reflecting, exploring, and encouraging the learner to debug his or her knowledge rather than apply principles attained during direct instruction" (Jonassen, 1996). These strategies are not overtly supported by traditional LMSs but are, as Jonassen asserts, incorporated into microworld, or virtual, learning environments.

One final design approach that may prove practical in guiding the design of a metaphorical, virtual world based on a social constructivist framework is Cyrs' (2000) IMPPACTS model. While this model was developed for use in a more traditional distance learning environment and as part of an instructional systems approach to design, it takes on new meaning when applied in the context of teaching and learning in the type of virtual world environment to be developed. This eight-component model offers a model for designing an onl ine activity or unit. The instructor and learners are free to arrange, organise, and engage in these eight components in virtually any order rather than having to follow a more linear/sequential process of moving from one component to the next. IMPPACTS serves as an acronym for Introduce, Motivate, Present, Practice, Apply, Communicate, Transfer, and Supplement. While an instructional module may include all of these components, it is not necessary to include every component for every activity developed. The use of this model ensures that instruction is considered from multiple perspectives; that a lesson is not entirely based on a didactic presentation and that application and transfer are integrated as part of the overall design. Spaces could be built into the world to introduce students to various concepts; tools could be pr ovided for application and 
communication; and, resources can be offered to support transfer and to supplement the learning.

\subsection{How have my views on these issues changed as a result of my participation in the 2006 IADIS Web Based Communities Conference?}

The IADIS Web Communities Conference held in Spain in February 2006 afforded me the opportunity to share the above ideas in a publ ic forum and to discuss them with colleagues asking similar questions. I soon realised that despite the fact that all the conference participants were there to learn more about web based communities, each approached this issue from a different perspective on $\mathrm{w}$ hat actually considered a ' web based community' and ho w 'community' should be defined. For some, working in a community was synonymous with collaborative activity; for others it required a collective response or approach to solving a problem. Still others focused on the importance of interaction or building connections. I heard about how blogs, wikis, and online forms could be used to create and manage communities of learners. I heard others discuss ways in which the interactions between and among the learners using these tools could be tracked and measured. Whether the presenters were teachers, designers, researchers, developers, psychologists, or sociologists, each had a di fferent definition of what constituted a web based community.

Few others at the conference shared my approach to building communities in 3D virtual worlds. Rather, most discussed community in terms of 2D web spaces or through the use of web based tools. The tools and ap proaches described at the conference varied but most provided users with 2D online or face-to-face opportunities to interact with one another, contribute to a shared project, establish connections with others, and build collaborative partnerships. Subsequently, my presentation of a 3D virtual world to promote and support community among my students resulted in a variety of questions, revealing my audience's response ranging from approval to skepticism. Besides the concern that some had about the amount of time, energy, and resources required to build and manage such a $3 \mathrm{D}$ environment, there was one question in particular that remained with me after the conference: "What value is there to providing a 3D interface?" In other words, they wanted to know what this technology allowed my students to do that they could not do in another way with some other tool? It was a good question and one that I struggled to answer.

When this question was posed to me at the end of my presentation, I responded by talking about the issue of presence as discussed above. Others at the conference had talked about presence and its value in terms of community. I too believed that presence could contribute to a sense of community and that it had s ignificant potential in terms of teaching and learning. However, at the time of my presentation, I had not yet taught a course in a virtual world and did not have an ex ample to share that illustrated this position. Since then, I have taught four courses in a virtual world and now have firsthand knowledge of the importance of presence in a teaching and learning environment.

The virtual world we have now developed incorporates many of the $2 \mathrm{D}$ technologies that others mentioned at the conference. We provide students with access to discussion boards, blogs, chat rooms (both text and audio), and wikis. We are constantly searching for other powerful tools to support the type of learning we believe our students should be engaged in. However, the most powerful example of community I have yet seen in my courses has actually emerged in the 3D space itself, 'in between' my students' use of these other tools. 
Before I began teaching in the virtual world, I used believe that I needed to have a 24 -hour presence in the world to ensure that my students had the support they needed while working in the world. This, of course, was one of the concerns that my audience had of teaching in this world. It also seemed to them that teaching in such a synchronous environment would require that I be logged in constantly to teach and monitor my students. Of course, I soon found out that this was next to impossible to do with all the other distractions of work and life. My fears of not always being logged into the world were soon realised when I opened my e-mail one morning and found three e-mail messages from one of my students. I opened the first e-mail, titled 'I'm lost'. My student had been wandering around in the virtual world for two hours and had yet to find anything that looked familiar. She was lost and was about to give up. I almost responded immediately but decided to read the other two messages first.

The next one, titled 'Call me please', noted that she had finally found the course space (made up of buildings facing a central plaza) but could not remember where any of the course tools or resources was located. She had now spent an additional hour searching for these without success. The third and final e-mail, 'I finally got in', shared the following, 'I got it. Finally. So stressful. It was not logging me in properly when I tried to enter [the] poster. Fellow students were in there with me just now and we all had a little trouble but we got in. It is cool if I can figure it out. Sorry to bother you so much'. Needless to say, I was very excited by this development. Not only had she successfully found the course; she did so with the help of her fellow students.

I learned two things from this student and her experience in the world. First, I learned that presence is indeed a powerful aspect of this 3D space. While other students could have posted tips or advice for logging in or accessing resources, it does not matter when the student who is lost cannot even find the message board. More importantly, the ability for a student's avatar to literally (or virtually) reach out a hand i $n$ aid of another is, at least from my perspective, the making of a community. Since this happened, I have had several other students share with me similar experiences in which other students approached and as sisted them inside the world. Second, I learned that my students do not need me in the way that they once did. That's not to say that I do not play an important role in the learning community that I hoped to create. Rather, I learned that my students have taken responsibility for their own learning and that they are finally viewing me as a facilitator of learning rather than as the fountain of all knowledge in the course.

\subsection{How can these observations evolve into a plan for a research study on my use of the virtual world?}

A recent international cooperation between Lindy McKeown, an educ ator and trainer in Australia, and myself has created an opportunity to consider yet another potential pedagogy for teaching and learning in a virtual world. My recent introduction to Action Learning (Dick, 1997) has subsequently led to a reconceptualisation of the teaching of library science courses at Appalachian State University. The introduction of Action Learning coupled with the 3D virtual learning environment immerses students in a social constructivist learning space that incorporates and supports exploration, planning, action, and reflection. Opportunities afforded by the 3D world maximise social presence using a range of theoretical frameworks to investigate student-teacher interactions.

The virtual world exists on an A ctiveworlds, Inc. universe server hosted at Appalachian State University and provides a three-dimensional space in which students adopt an avatar to move through the space and interact with others in real time using a text-based chat tool. Other tools 
are incorporated into the world, including blogs, discussion boards, wikis, web pages, library databases, and audio chat rooms, providing students a plethora of ways to participate and engage in a community of practice. A central plaza around which a variety of buildings have been constructed to provide access points to tools and resources, and spaces for interactions and collaborations (Figure 1). Students' ability to see other avatars and interact with them (talk, walk, wave, etc.) encourages serendipitous interactions and promotes a gr eater sense of presence than other text-based learning management systems.

This learning environment supports the five assumptions of our college's conceptual framework about teaching and I earning. It provides a s pace in which community can be formed and nurtured. Students know and can see when their colleagues are logged into the world. The can walk up to them, wave, and talk to them about life, work, or the latest news. Through these interactions, both planned and s erendipitous, students begin to create knowledge together. They talk about the work they are doing in class, they share ideas, processes, and resources with one another and contribute to the base of knowledge that exists in their field. Throughout this process, they move from novice to expert, both in terms of knowledge and skills, but also in terms of their abilities to work collaboratively and inside a virtual learning environment using tools previously unknown to them. Their beliefs about teaching and learning are challenged, refined, and shaped by the process of learning together in an authentic social world of dialogue and discovery.

Figure 1 Avatar in the commons

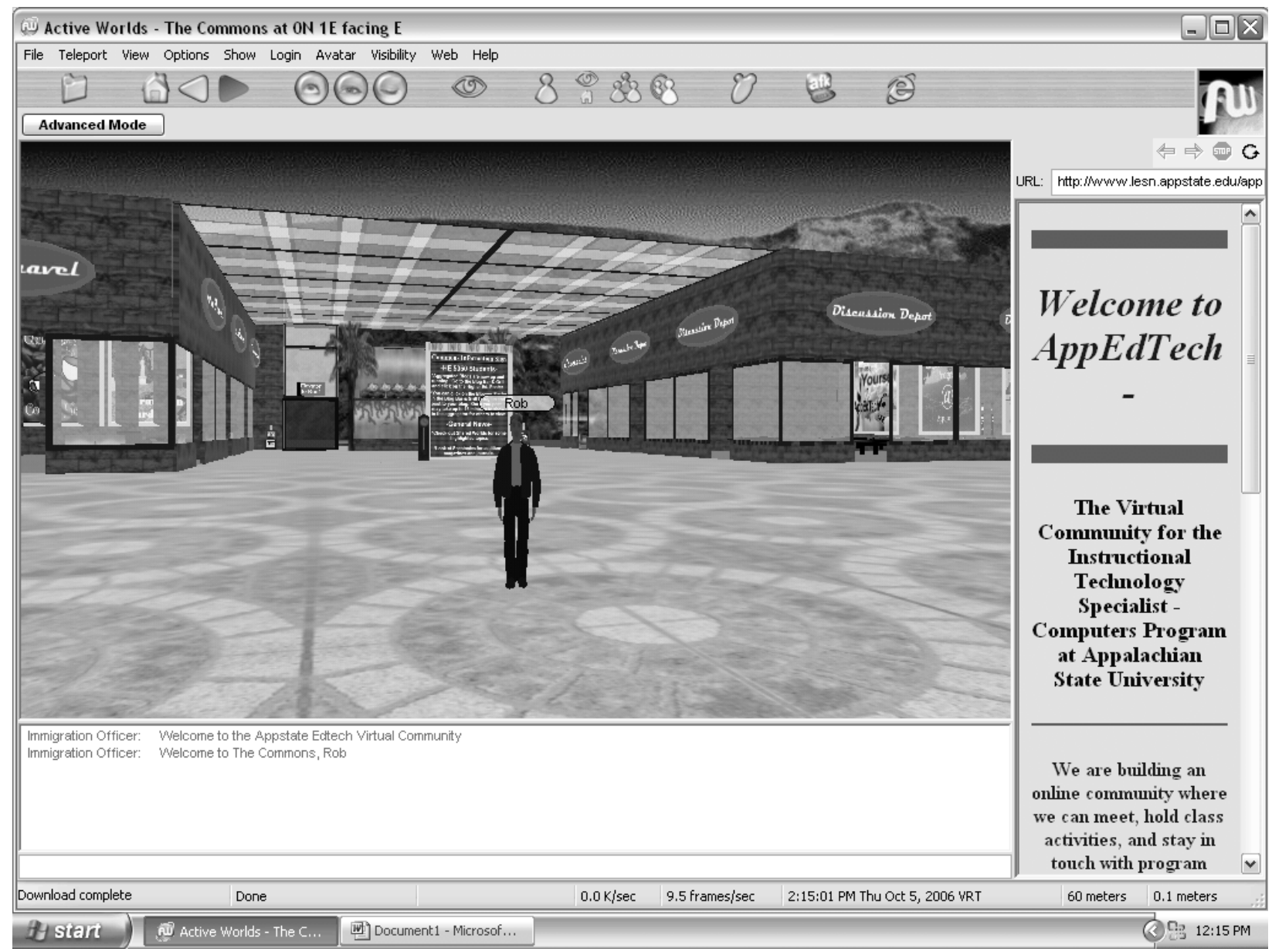


The focus of our upcoming study will be on building a bridge between theory and practice by providing my students with a tool set that promotes personal and social reflection, and creates and scaffolds a community of practice. The Action Learning pedagogy will be implemented in four sections of library science course titled, The School Media Programme and in two sections of Designing Adult Learning Experiences. A total of 75 graduate students will be participating in the six courses, with each student identifying a significant challenge or problem to address in his or her own action learning project. Utilising core learning episodes, reflective journals, and learning sets, each student will develop an action learning plan to systematically explore, plan, act, and reflect regarding their chosen topic or issue. At the end of each course, students will participate in a course 'professional learning expo' to share their findings with their colleagues. Each student's action learning project will be unique to their professional and academic needs and interests within the parameters for the course description. Students will be expected to meet regularly with a small group of other students (learning set) and post comments, questions, ideas, and suggestions to a discussion board. Each student will maintain a blog for reflective commentary about their respective projects as they move through the action learning cycle of exploration, planning, acting, and reflecting. The virtual world provides the space in which students can meet together, interact with students and faculty, access course and project resources, and contribute to discussions and blogs. Core learning episodes are lessons or activities that can be requested by the students to address immediate learning needs related to the student projects. A core learning might be a lesson on web design for students interested in creating a web page as part of his or her action learning project. It could also consist of a lesson on online search strategies and tools to assist students with the exploration phase of their projects.

The 3D virtual environment described above will be us ed to support communication and collaboration among the students enrolled in the course. This virtual environment will provide access to tools and resources necessary for the successful completion of the students' action learning projects and, more importantly, will offer an immersive learning space in which it is believed that an increased sense of presence can contribute to the students' social construction of skills and knowledge within a community of practice.

Survey data, observations of student engagement in the virtual environment, and document analysis of student e-mail, blogs, and discussion board posts will be used to collect and analyse data in order to answer the research question, 'How can university faculty bridge the gap between theory and pr actice to develop a c ommunity of practice comprised of reflective professionals and lifelong learners?' These data will provide a rich qualitative case study of the students' process of planning, acting, and reflecting, and how this process can be us ed to develop best practices, refine theory, and develop critical thinking skills. Survey and observation tools will be developed in Spring 2007 and data collection will commence in Summer 2007.

This study is based on extensive research in the field of Action Learning by Dick (1997), McKeown and O bstoj (2004), Pedler (1991) and Weinstein (1995); in the area of Action Research by Farmer (2003), Kember (2000) and Parsons and Brown (2001); in virtual learning environments by Riedl et al. (2005), Dickey (2000; 2002), Sanders and Tashner (2004); and on the topic of social presence by Gunawardena and Zittle (1997) and Gunawardena et al. (1997). The findings of this study will have significant implications for the teaching of graduate students in library science and higher education. The pedagogy of Action Learning offers educators a powerful approach for engaging adult learners in a reflective process that involves collaborative problem-solving, strategic planning, and ongoing professional growth. Student responses to the survey questions will provide rich data to assist us in identifying ways in which theory and practice can be connected in the context of action, reflection, and social interaction. 


\section{CONCLUSION}

There is still much to learn about the potential of this new learning technology and its capacity to support constructivist learning environments. Further research is necessary to help identify models for designing new approaches for teaching and to further our understanding of how learning occurs in a virtual world. I am inspired by what others have done before me and by what I believe to be possible. With my college's social constructivist framework in hand, I intend to continue asking the questions discussed above and aspire to develop a world in which the spaces support activities that are designed according to our framework's five assumptions. In this world, I expect students to begin forming the basis for the kind of community of practice in which learning emerges out of their participation in the community and their interdependence upon one anot her. Perhaps the pedagogy of Action Learning can provide that structure necessary to create such a learning community.

As a r esult of the 2006 Web Based Communities Conference, I am now part of a I arger conversation about community and how web technologies can be used to create and support different types of communities. My own understandings of this were both affirmed and challenged at the conference, leading me consider other alternatives and ask myself different questions than when I first submitted this paper. I look forward to the 2007 c onference to continue the dialogue and s hare the results of the research study I plan to conduct in the coming semester.

\section{REFERENCES}

Bishop, M.J. and Cates, W.M. (1996) 'A door is a big wooden thing with a knob: getting a handle on metaphorical interface design', Proceedings of Selected Research and Development Presentations at the 1996 National Convention of the Association for Educational Communications and Technology, ERIC Document Reproduction Service No. ED397779, Indianapolis, IN.

Cates, W.M. (1994) 'Designing hypermedia is hell: metaphor's role in instructional design', Proceedings of Selected Research and Development Presentations at the 1994 National Convention of the Association for Educational Communications and Technology, ERIC Document Reproduction Service No. ED373706, Indianapolis, IN.

Collins, M. and Berge, Z. (2001) 'Facilitating interaction in computer mediated online courses', http://www.emoderators.com/moderators/flcc.html (accessed 4 August 2005).

Cyrs, T.E. (2000) The Distance Learning Workshop for Your Creative Teaching, Las Cruces, NM: Educational Development Associates.

Dick, B. (1997) 'Action learning and action research', http://www.scu.edu.au/schools/gcm/ar/arp/ actlearn.html.

Dickey, M.D. (2000) 3D Virtual Worlds and Learning: An Analysis of the Impact of Design Affordances and Limitations of Active Worlds, Blaxxun Interactive, and OnLive! Traveler; and a Study of the Implementation of Active Worlds for Formal and Informal Education, Columbus, $\mathrm{OH}$ : The Ohio State University.

Dickey, M.D. (2002) 'Constructing learners in 3D: an investigation of design affordances and constraints of active worlds educational universe', Proceedings of AECT 2002, Dallas, TX, November.

Farmer, L.S.J. (2003) How to Conduct Action Research: A Guide for Library Media Specialists, Chicago: ALA.

Gunawardena, C.N., Lowe, C.A. and Anderson, T. (1997) 'Analysis of a global online debate and the development of an interaction analysis model for examining social construction of 
knowledge in computer conferencing', Journal of Educational Computing Research, Vol. 17, No. 4, pp.395-429.

Gunawardena, C.N. and Zittle, F. (1997) 'Social presence as a predictor of satisfaction within a computer mediated conferencing environment', The American Journal of Distance Education, Vol. 11, No. 3, pp.8-25.

Henry, A. and Crawford, C.M. (2001) 'Creating a collaborative web-based environment through the inclusion of metaphorically enhanced graphics', Proceedings of WebNet 2001: World Conference on the World Wide Web and Internet, ERIC Document Reproduction Service No. ED462914, Orlando, FL.

Jonassen, D.H. (1996) Computers in the Classroom: Mindtools for Critical Thinking, Englewood Cliffs: Prentice Hall.

Kember, D. (2000) Action Learning and Action Research: Improving the Quality of Teaching and Learning, Sterling, VA: Stylus Publishing, Inc.

McKeown, L. and Obstoj, T. (2004) 'Bridging the knowing-doing gap: using action learning as a methodology for ICT professional development', Paper Presented at the 2004 Australian Computers in Education Conference, Adelaide, Australia, July.

Palloff, R.M. and Pratt, K. (1999) Building Learning Communities in Cyberspace: Effective Strategies for the Online Classroom, San Francisco: Jossey-Bass Publishers.

Papert, S. (1980) Mindstorms: Children, Computers, and Powerful Ideas, New York: Basic Books.

Parsons, R.D. and B rown, K.S. (2001) Teacher as Reflective Practitioner and Action Researcher, Belmont, CA: Wadsworth Press.

Pedler, M. (Ed.) (1991) Action Learning in Practice, Aldershot, Hants: Gower.

Reich College of Education (2005) Conceptual Framework, 29 September, Appalachian State University Reich College of Education, http://www.fd.appstate.edu/rcoe_framework/cover _page.htm (retrieved 29 September 2005).

Riedl, R., Tashner, J.H. and B ronack, S. (2005) 'Innovation in learning: assumptions about teaching in a virtual world', Paper Presented at the 2005 International College Teaching Methods and Styles Conference, Reno, NV, September.

Sanders, R.L. and Tashner, J. (2004) 'Virtual worlds...metaphorical worlds: design for learning', Proceedings of the League of Worlds Conference, Helsinki, Finland, http://www.leagueofworlds.com/old/papers/sanders2.html (accessed 30 May 2005).

Watkins, R. and Kaufman, R. (2003) 'Strategic planning for distance education', in M.G. Moore and W.G. Anderson (Eds.) Handbook for Distance Learning, Mahwah, NJ: Lawrence Erlbaum Associates.

Weinstein, K. (1995) Action Learning: A Journey in Discovery and Development, London: Harper Collins. 